\title{
Água de chuva domiciliar no esgoto separador absoluto
}

Data de entrada: 26/10/2016

Data de aprovação: $13 / 11 / 2017$

\section{Resumo}

Sistemas de esgotamento sanitário separadores absolutos são concebidos para não receber contribuição de águas pluviais, mas não é raro haver contribuição de água de chuva decorrente de ligações prediais irregulares. $\mathrm{O}$ objetivo deste trabalho foi identificar a região com maior contribuição de água pluvial em lotes urbanos, quantificar esse fenômeno numa área amostral e estimar o fenômeno para toda a bacia. Os dados georreferenciados de vistoria ambiental da área mais antiga foram tratados pelo software ArcGis para selecionar a área modelo. Foi realizada uma vistoria com entrevista nos imóveis para detectar o fluxo cruzado e medir a área impermeável. A vazão da rede de esgoto a jusante da área modelo selecionada foi quantificada e comparada à vazão global de água da chuva, a qual foi determinada com uso do índice de precipitação, sua duração e a área predial impermeável. Concluiu-se que a contribuição de água pluvial era cinco vezes superior ao volume de esgoto predial e que houve extravasamento do esgoto no momento da chuva. Palavras-chave: Sistema de esgotamento sanitário. Ligações irregulares. Afluxo pluvial no esgoto. Separador absoluto.

\section{Abstract}

These systems are designed so that they don't receive pluvial water contribution; however this occurrence isn't unusual due to irregular building connections. The purpose of this study was to identify the zone with the highest rainwater contribution originated from buildings, to measure this phenomenon in a model area and to assess such occurrence for the entire basin. The georeferenced data of environmental inspection in the oldest area was processed by ArcGIS software in order to select the model area. An environmental survey with interview was conducted to detect the cross-flow and to measure the impermeable area. The sewage flow towards the selected downstream model area was quantified and compared to the global rainwater flow, which was determined based on the precipitation index, its duration and the impermeable land area. We concluded that the rainwater contribution was five times above the sewer building volume and that there's sewage overflow at rainfall. Keywords: Sewage system. Illicit sewage connections. Inflow of rainwater into the sewer. Separated sewer systems.

\footnotetext{
Murilo Bertolino - Mestre em Meio Ambiente Urbano e Industrial. Engenheiro da Sanepar (Companhia de Saneamento do Paraná). Jonas Heitor Kondageski - Mestre em Engenharia de Recursos Hídricos e Ambiental. Engenheiro da Sanepar (Companhia de Saneamento do Paraná).

Regina Weinschutz - Doutora em Engenharia Química. Professora da UFPR (Universidade Federal do Paraná).

*Endereço para correspondência: Av. Marechal Deodoro, 3081, Curitiba, Paraná - CEP: 80.045-375. Telefone: (41) 3538-1827. E-mail: mubertolagmail.com.
} 


\section{INTRODUÇÃO}

A NBR 9648/86, sobre o estudo de concepção do sistema de esgotamento sanitário separador, considera a contribuição parasitária, ou seja, infiltração do lençol freático, mas não contempla o afluxo direto de água de chuva (TSUTIYA E SOBRINHO, 2011). A infiltração parasitária compreende a água que penetra nas tubulações da rede coletora de esgoto através de juntas inadequadas e imperfeições nas paredes dos condutos, bem como água que penetra no sistema através dos poços de visita (AZEVEDO NETTO, 1979). Por sua vez, o afluxo direto é o encaminhamento indevido de águas pluviais prediais, assim como a ligação de galerias de águas pluviais à rede coletora de esgoto (METCALF E EDDY, 1991; AZEVEDO NETTO, 1998).

O aporte de água pluvial na rede de esgoto provoca sobrecarga na rede coletora, nas estações de bombeamento e nas estações de tratamento, podendo desestabilizar o sistema. Isso pode exigir o lançamento dos efluentes nos corpos receptores sem o devido tratamento (TSUTIYA E SOBRINHO, 2011). Os sistemas de esgotamento sanitário utilizados no Brasil sofrem com sobrecargas de água de chuva devido às infiltrações e às ligações irregulares. $O$ aumento da vazão nos sistemas de esgotamento, em dias chuvosos, pode chegar a $283 \%$ quando comparado com a vazão máxima em dias secos (TSUTIYA E BUENO, 2004). Outros países têm tido o mesmo problema. Em 1992, o Projeto Rouge foi iniciado com o objetivo de meIhorar a qualidade da água na bacia hidrográfica do rio Rouge, no estado de Michigan (EUA). Esse estudo detectou a existência de 5.260 descargas ilícitas, sendo que a qualidade da água só seria melhorada se as ligações irregulares fossem eliminadas (JOHNSON E TUOMARI, 1998).

Em Portugal, os sistemas de esgoto apresentavam problemas devido ao aporte de água por infiltração e de ligações pluviais irregulares. Dessa forma, a definição de mecanismos para detectar e cor- rigir esses problemas é, particularmente, crítica (MACHADO et al., 2007). Na Polônia, a influência das fortes chuvas que ocorreram sobre pequenas estações de tratamento de esgoto localizadas na Cracóvia, em 2010, revelou que a quantidade de água pluvial encaminhada ao sistema de esgoto aumentou entre 163 e $343 \%$ em relação ao ano de 2008, sendo que a precipitação anual, em 2010, foi $65 \%$ maior que em 2008 . Esse aumento na vazão ocasionou um custo maior no tratamento de aproximadamente 700\% (KACZOR, 2011).

Muitos modelos têm sido propostos para avaliar as parcelas de contribuição provenientes de afluxos diretos e de infiltração em sistemas separador absoluto. Esses modelos são estabelecidos a partir da avaliação da vazão em função do tempo (ZHANG, 2005; RAYNAUD et al., 2011). As parcelas de contribuição têm ações de gerenciamento distintas, como a utilização de materiais mais adequados pela empresa de saneamento e pela administração pública de águas pluviais com uso de obras planejadas e integradas por estas. Além disso, as ligações prediais não são responsabilidade das entidades acima, mas sim de seus usuários. Esses devem interligar suas contribuições de esgoto e de água pluvial de maneira correta, com o auxílio de profissionais habilitados, de modo a não misturar os efluentes prediais. Desse modo, as empresas de saneamento realizam campanhas para encontrar as ligações irregulares, mas não possuem poder de penalizar os moradores interligados de forma irregular, ficando essa tarefa sob a responsabilidade das autoridades municipais. Portanto, mesmo que se identifique a fonte do problema, existe grande dificuldade em solucioná-lo.

Dentro do exposto, o objetivo deste estudo foi estimar a contribuição pluvial de origem predial no sistema de tratamento de esgoto Belém, em período de chuva, com base nas informações da região com maior contribuição. 


\section{METODOLOGIA}

\subsection{Determinação da área de estudo}

O sistema de esgotamento da área de estudo foi escolhido considerando a região mais antiga de esgotamentos sanitários da cidade de Curitiba-PR, os históricos de excesso de vazão na entrada da estação de tratamento em dias chuvosos, bem como os dados de vistorias pré-existentes na Sanepar, nos quais havia constatação de ligações prediais irregulares de rede de esgoto e de águas pluviais. A área específica de estudo foi definida com a ferramenta "Density" do software Arcgis da ESRI (Environmental Systems Research Institute, EUA). As coordenadas geográficas e as condições observadas pelos agentes de vistoria estavam disponíveis no banco de dados. No caso, a condição selecionada foi ligações irregulares de água de chuva na rede de esgoto. Posteriormente, uma planta específica com densidade de irregularidade foi criada para identificar a maior concentração deste problema. Três áreas foram identificadas com maior frequência de casos, sendo que $\mathrm{a}$ área com maior densidade de irregularidades foi escolhida. A área escolhida conta com 427 residências, sendo que 81 foram relacionadas no banco de dados com irregularidade de lançamento de água de chuva na rede coletora de esgoto.

\subsection{Vistorias técnicas ambientais}

Depois da área definida, foi elaborado um relatório com base no banco de dados contendo todas as economias dentro da área selecionada. Nova vistoria ambiental em todas as economias foi realizada para verificar ligação cruzada entre a rede de esgoto e a pluvial. Durante a vistoria, o técnico verificou a construção predial e realizou um teste com administração de $50 \mathrm{~mL}$ de dois corantes distintos (vermelho, azul ou amarelo), um no ponto predial de esgoto e outro no de água de chuva para verificar se estão interligados de maneira correta com acompanhamento visual de sua saída no sistema de esgotamento sanitário ou galeria pluvial. Nos casos em que foram detectados ligações irregulares ou problemas nas li- gações, os clientes foram informados e notificados para a correção.

A medição da área de contribuição foi realizada no momento da vistoria técnica utilizando a NBR 10.844, 1989 para as economias que apresentavam ligação cruzada. Adicionalmente, um questionário foi aplicado para conhecer o perfil do usuário do sistema de esgotamento sanitário e elucidar o motivo da irregularidade. Para as economias listadas no banco de dados com irregularidade de água de chuva na rede de esgoto, onde não foi possível realizar a nova vistoria, a área de contribuição foi estimada com uso do software Google Earth.

\subsection{Vazão, pluviometria e tempo de retorno da chuva}

Ovolume de água da chuva na rede coletora é a soma da contribuição de cada residência, a qual foi calculado utilizando a área de contribuição e a quantidade de chuva $(\mathrm{mm})$ determinada pelo pluviômetro portátil LACROSSE (modelo WS2812) instalado na área de estudo. Este determinava o volume a cada 5 min. Um medidor de vazão portátil do tipo ultrassônico HACH (modelo Sigma 910) foi instalado no poço de visita a jusante da área de estudo para determinar o acréscimo de vazão nos períodos de chuva.

O tempo de retorno (TR) da precipitação estudada foi determinado pela Equação $1 \mathrm{com}$ a intensidade de precipitação (i), e o tempo de duração ( $t$ ) extraído do pluviômetro que foi instalado no local.

$\mathrm{i}=\frac{5.950,00 \times \mathrm{T}_{\mathrm{R}}^{0,217}}{(\mathrm{t}+26)^{1,15}}$

Onde i - é a intensidade da chuva expressa em milímetros por hora; $t$ - é o tempo de duração expresso em minutos; $T_{R}$ - é o tempo de recorrência expresso em anos (FENDRICH, 1998).

O volume de efluente dentro da rede de esgotamento foi determinado pela área abaixo da curva da medição de vazão. $O$ método para o cálculo da 
área foi baseado na soma de Riemann, teoria fundamental de cálculo integral, em que são somadas as áreas de diversos trapézios para chegar à área aproximada (FINNEY, 2005).

\subsection{Afluxo na rede de esgoto}

A metodologia relatada por Metcalfe Eddy (2003), por meio do gráfico da vazão pelo tempo, foi usada para determinar o afluxo direto, ou seja, pico de vazão no período de chuva em relação ao período de estiagem. A diferença entre as áreas obtidas do histograma em dias secos e chuvosos representa o volume de água da chuva que adentra na rede coletora. $O$ volume de água de chuva foi calculado com uso da área de contribuição impermeável das residências e o índice pluviométrico. $O$ volume de água de chuva medido nas residências e o volume obtido a partir da medida de vazão na rede de esgoto foram comparados para obter a parcela de contribuição na rede proveniente de ligações irregulares. $O$ volume unitário da economia foi usado para estimar o que acontece no âmbito de todo o sistema de esgotamento da bacia do rio Belém.

\section{RESULTADOS E DISCUSSÃO}

Curitiba, capital do estado do Paraná, é a maior cidade do estado e apresentava 1.751.907 habitantes em 2010 (IBGE, 2010). O sistema de esgotamento sanitário da bacia hidrográfica do rio Belém foi o primeiro sistema implantado (SCHUSTER,1994). Devido à sua idade, tamanho e localização central foi escolhido para a realização deste estudo. Como outros rios urbanos, o rio Belém apresenta afluência de ligações irregulares de diversas formas, como ligações irregulares prediais e ligações cruzadas com o sistema público de drenagem urbana. Um total de 261.180 economias estavam interligadas a essa bacia em junho de 2012 (SANEPAR, 2012), sendo que 6.115 (2,34\%) foram diagnosticadas com interligação irregular de água de chuva na rede coletora de esgoto com uso de vistoria técnica ambiental de rotina. Esses pontos de irregularidades apresentavam uma distribuição territorial (Figura 1) contendo três áreas de maior concentração. A área escolhida, por possuir a maior densidade de economias irregulares, chama-se conjunto Assucena e apresentava 81(18,97\%) ligações de esgoto com afluxo inadequado de água de chuva (Figura 1).

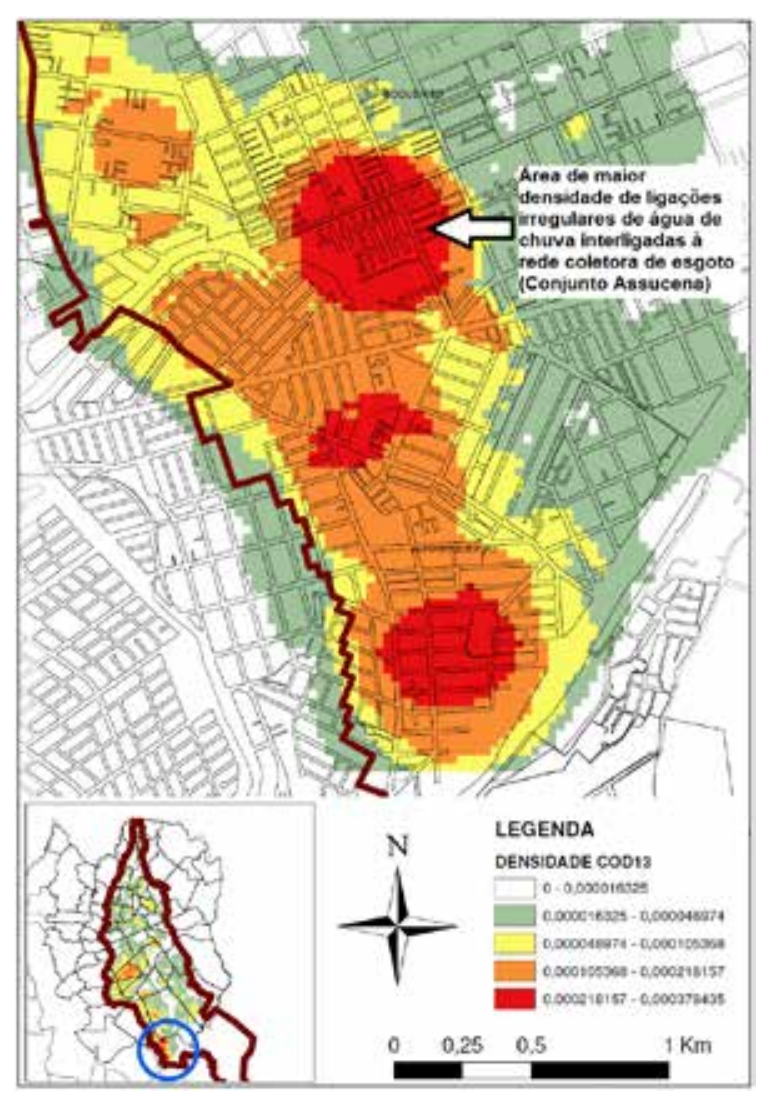

Figura 1- Localização da área de estudo dentro da bacia do rio Belém.

Fonte: adaptado de Sanepar - base cartográfica do cadastro técnico (2012).

A visita técnica ambiental revelou que havia problemas em alguns poços de visita, sem a canaleta de escoamento e em locais com a declividade insuficiente, porém sem interferir na avaliação de irregularidades das economias.

As reformas inadequadas observadas nas edificações do residencial Assucena estavam, geralmente, associadas à impermeabilização da área dos fundos do terreno e à interligação dos 
sistemas de águas pluviais e de esgotamento sanitário. Foi observado que 28 imóveis, os quais apresentavam informações de conformidade no banco de dados (SANEPAR, 2012), revelaram irregularidades após a vistoria, o que foi atribuído à reforma inadequada resultando na ligação cruzada. A companhia de saneamento faz a vistoria em edificações para autorizar o "habite-se", mas não tem controle sobre as reformas posteriores que não tenham alvará de construção e, consequentemente, não se realiza uma nova vistoria. Isso revela que a educação ambiental para conscientização da população é uma das ações que devem ser realizadas de forma continuada para evitar esse tipo de irregularidade.

Das 426 economias (Tabela 1), cerca de $72 \%$ puderam ser vistoriadas, sendo que em apenas $48 \%$ também foi realizado teste de cruzamento de efluente. $O$ teste não pôde ser realizado em alguns imóveis devido à impossibilidade de acesso à captação de efluentes. Cerca de $26 \%$ dos imóveis estavam sempre fechados nos horários disponíveis para a visita, e $3 \%$ dos moradores não permitiram a vistoria. No primeiro caso, a ausência de moradores para atender os técnicos pode ser atribuída ao estilo de vida urbano atual, enquanto a desautorização pode ocorrer devido à preocupação com situações de irregularidades. Isso revela que nem sempre é possível fazer a vistoria de forma adequada, o que fortalece a necessidade preventiva da vistoria de "habite-se", bem como a exigência desse procedimento para toda obra predial.

Tabela 1- Vistoria técnica das economias do residencial Assucena

\begin{tabular}{|c|c|c|}
\hline \multirow{2}{*}{ Situação na vistoria } & \multicolumn{2}{|c|}{ Economias } \\
\cline { 2 - 3 } & Número & Porcentagem \\
\hline Vistorias com realização de teste* & 202 & 47,4 \\
\hline Vistorias sem realização de teste* & 102 & 23,9 \\
\hline Imóveis fechados & 109 & 25,6 \\
\hline Não autorizada pelo morador & 13 & 3,1 \\
\hline Total & 426 & 100,0 \\
\hline
\end{tabular}

* teste de ligação cruzada com uso de corante.
Das 202 economias avaliadas com teste de corante, 78 apresentaram água de chuva interligada na rede de esgoto, ou seja, cerca de 39\%. A área de contribuição (NBR 10.844, 1989) correspondente é de 3.070,50 $\mathrm{m}^{2}$. A maioria desses moradores (76) declarou que não sabia que estava causando problema ao sistema, sendo que 68 deles declararam nem saber da ligação irregular; entretanto, 14 já haviam sido notificados anteriormente pela empresa de saneamento. Dentre os imóveis fechados (109) ou sem autorização de vistoria (13), o banco de dados da Sanepar (SANEPAR, 2012) mostrou que 41 economias possuíam ligação irregular da água de chuva na rede de esgoto. Nesse caso, a área de contribuição impermeável foi medida com o uso do software Google Earth para 38 economias e revelou 1.143,37 $\mathrm{m}^{2}$, ou seja, toda área de contribuição foi de 4.213,87 $\mathrm{m}^{2}$. Cabe salientar que 2 economias não apresentavam imagens adequadas para avaliação com o uso do software e uma terceira estava em reforma.

Houve seis eventos de chuva que foram acompanhados no período avaliado (Tabela 2). A "Chuva 4 " apresentou a maior precipitação $(28,5 \mathrm{~mm})$ e duração (255 min), sendo que, em uma única hora, correspondeu a uma chuva intensa com 13,2 mm.

Tabela 2- Precipitações ocorridas no período de medição

\begin{tabular}{|c|c|c|c|}
\hline Chuva & Data do evento & $\begin{array}{c}\text { Duração da } \\
\text { chuva (min) }\end{array}$ & $\begin{array}{c}\text { Precipitação } \\
\text { (mm) }\end{array}$ \\
\hline 1 & $16 / 01 / 2013$ & 75 & 5,1 \\
\hline 2 & $18 / 01 / 2013$ & 70 & 10,3 \\
\hline 3 & $23 / 01 / 2013$ & 25 & 1,3 \\
\hline 4 & 02 e $03 / 02 / 2013$ & 255 & 28,5 \\
\hline 5 & $03 / 02 / 2013$ & 70 & 7,7 \\
\hline 6 & $03 / 02 / 2013$ & 10 & 5,6 \\
\hline
\end{tabular}

O tempo de retorno calculado com dados da "Chuva 4" revela uma probabilidade de novo evento com a mesma importância a cada 4 dias. Logo, a contribuição pela água pluvial na rede de esgoto é um fenômeno que ocorre com alta frequência e deve ser 
evitado, pois o sistema de esgotamento sanitário entra em colapso com a entrada de água de chuva na rede coletora e a saída de esgoto para os córregos e solo (BÉNÉDITTIS E BERTRAND, 2013).

Ao se comparar somente o volume de chuva precipitado, há uma diferença muito acentuada entre a "Chuva 4" (figura 4 e 5) e a "Chuva 1" (Figura 3). Como sabemos, por meio dos gráficos de vazão, que os dias de chuva possuem um pico de afluxo em relação aos dias secos e que a vazão medida na rede coletora de esgoto não demonstra diferença quanto ao pico de vazão de afluxo, que é de aproximadamente $20 \mathrm{~L} . \mathrm{s}^{-1}$ tanto para a chuva de $5,1 \mathrm{~mm}$ como para a chuva de $28,5 \mathrm{~mm}$, fica caracterizado então que há extravasamento de esgoto no sistema.

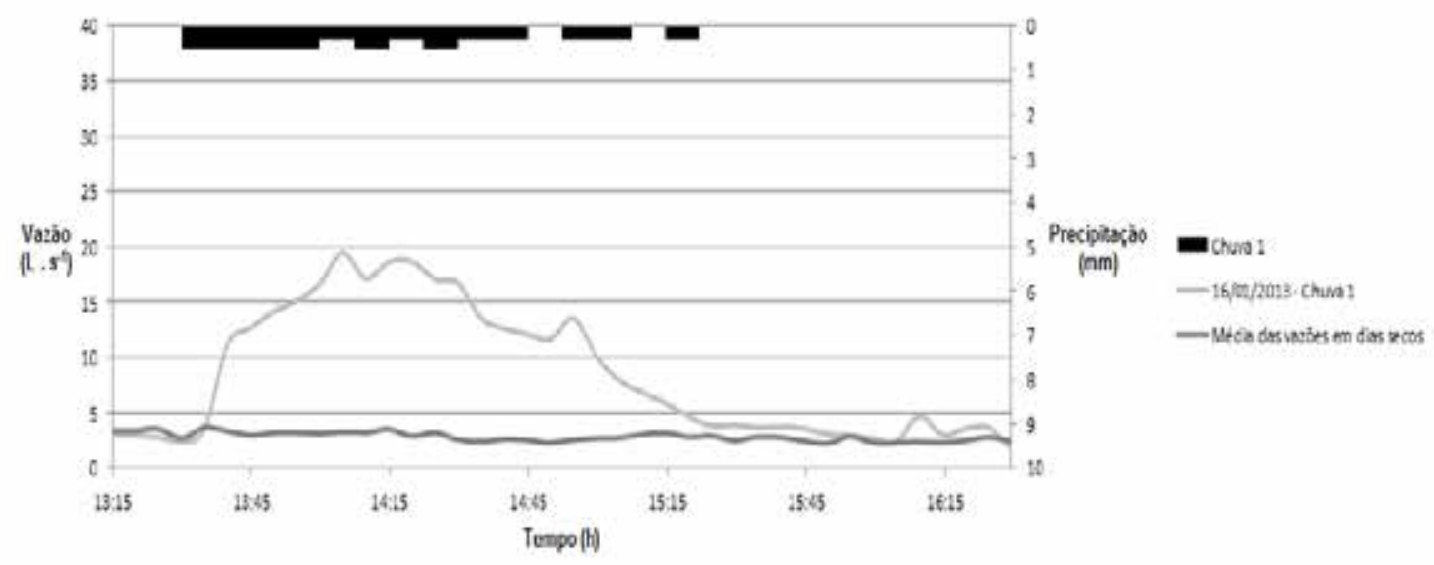

Figura 2- Hidrograma do período da chuva-1 para vazões do conjunto Assucena comparando dias secos com o dia de chuva e a intensidade da chuva

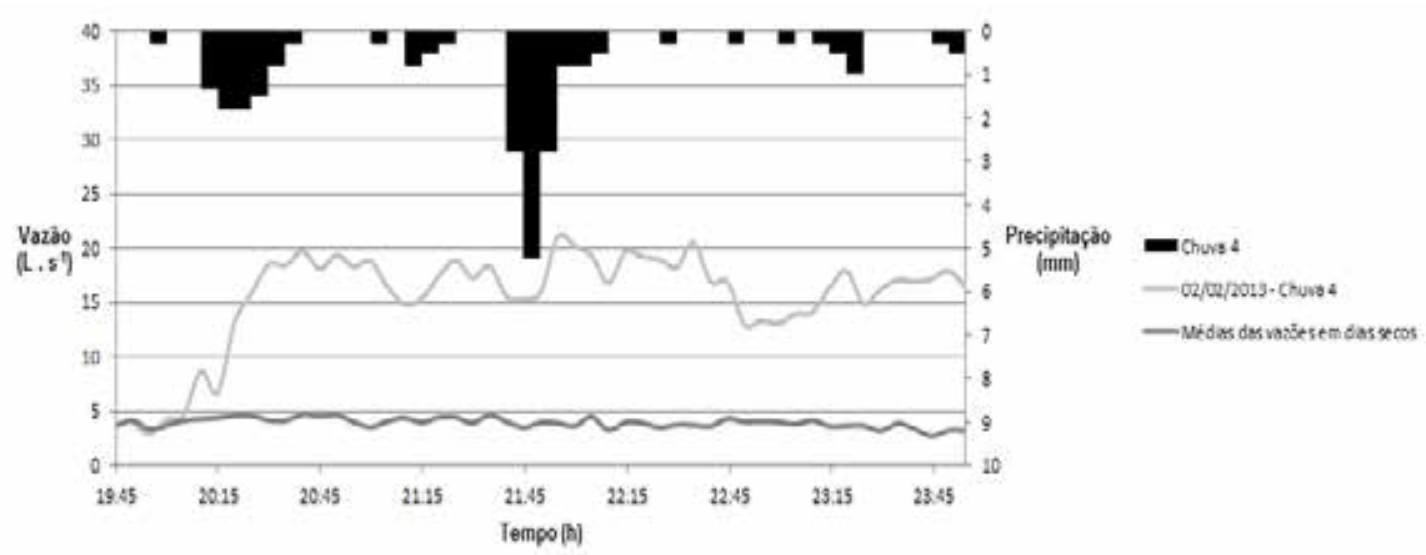

Figura 3- Hidrograma do período da chuva-4 para vazões do conjunto Assucena comparando dias secos com o dia de chuva e a intensidade da chuva 


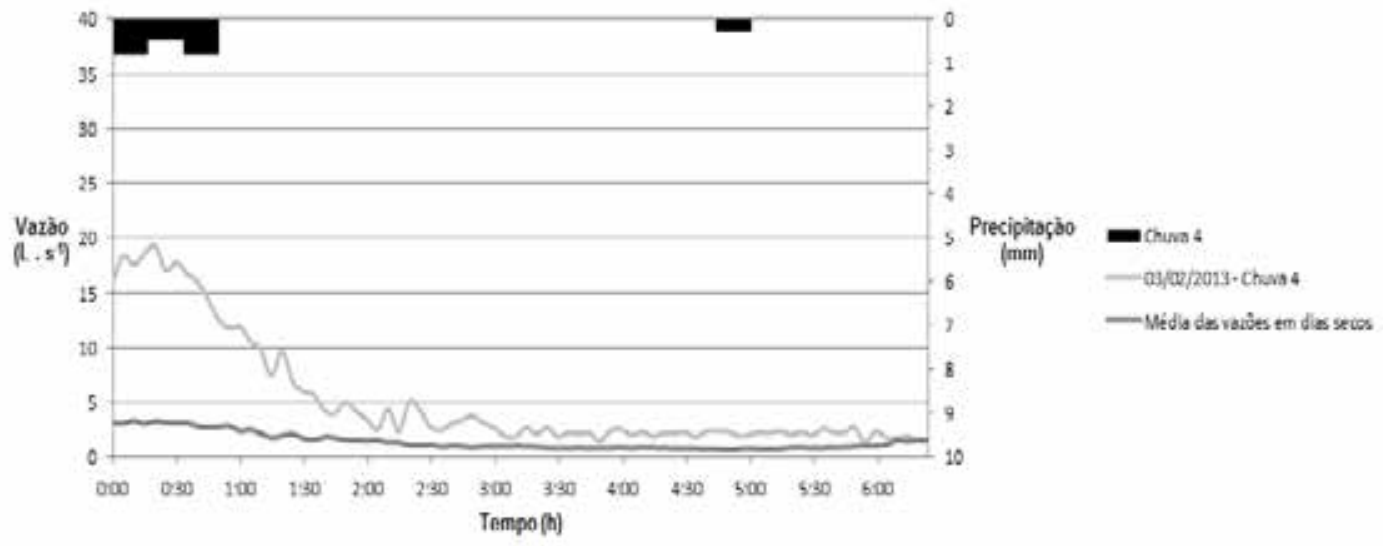

Figura 4- Hidrograma do período da chuva-4-continuação para vazões do conjunto Assucena comparando dias secos com o dia de chuva e a intensidade da chuva

O ponto de medição de vazão recebeu em tempo seco um volume de $33,89 \mathrm{~m}^{3}$, sendo que atingiu $101,23 \mathrm{~m}^{3}$ para a "Chuva 1". Nesse evento, a contribuição estimada pelas ligações irregulares foi de 15,66 $\mathrm{m}^{3}$ (Tabela 3). Isso revela que também há outras fontes de contribuição. A maior parcela é proveniente de falhas no próprio sistema de esgotamento sanitário, pois a diferença entre o dia seco e o período da chuva resulta em um volume de $67,34 \mathrm{~m}^{3}$. Portanto, somente $23 \%$ do volume de afluxo provém de ligações irregulares. Ess e fato demonstra que o sistema necessita de intervenções da companhia de saneamento.

Tabela 3 - Volume de água de chuva destinado à rede coletora de esgoto durante os períodos de medição.

\begin{tabular}{|c|c|c|c|c|c|}
\hline Chuva & $\begin{array}{c}\text { Área impermeável } \\
\text { das residências } \\
\text { vistoriadas } \mathbf{( m}^{\mathbf{2}} \mathbf{)}\end{array}$ & $\begin{array}{c}\text { Tempo de } \\
\text { duração da } \\
\text { chuva } \mathbf{( m i n )}\end{array}$ & $\begin{array}{c}\text { Precipitação } \\
\mathbf{( m m )}\end{array}$ & $\begin{array}{c}\text { Volume total destinado } \\
\text { à rede coletora de } \\
\text { esgoto } \mathbf{( m}^{\mathbf{3}} \mathbf{)}\end{array}$ & $\begin{array}{c}\text { Vazão média } \\
\mathbf{( I . S}^{-1} \mathbf{)}\end{array}$ \\
\hline 1 & $3.070,50$ & 70 & 5,1 & 15,66 & 3,73 \\
\hline 2 & $3.070,50$ & 65 & 10,3 & 31,63 & 8,11 \\
\hline 3 & $3.070,50$ & 20 & 1,3 & 3,99 & 3,33 \\
\hline 4 & $3.070,50$ & 250 & 28,5 & 87,51 & 5,83 \\
\hline 5 & $3.070,50$ & 65 & 7,7 & 23,64 & 6,06 \\
\hline 6 & $3.070,50$ & 45 & 5,6 & 17,19 & 6,37 \\
\hline TOTAL & & & & 179,62 & \\
\hline
\end{tabular}

A maior intensidade da "Chuva 4", 5,2 mm (Figura 4), corresponderia a uma vazão de 53,2 L.S ${ }^{-1}$ de água de chuva no sistema de saneamento, sendo que o valor admitido neste sistema é na ordem de $20{\mathrm{~L} . \mathrm{s}^{-1}}^{-1}$ (Figura 4). $O$ valor que não é admitido no sistema, 33,2 L.s ${ }^{-1}$, produzirá problemas ao cidadão, como inundação de áreas urbanas ou dos próprios imóveis.

A contribuição unitária para uma economia interligada de forma irregular é de $0,68{\mathrm{~L} . \mathrm{s}^{-1}}^{-1}$ isso no pico de maior vazão, para uma chuva dessa grandeza, que pode se repetir a cada 4 dias e para uma área impermeável média entre as residências vistoriadas. Esse valor extrapolado para todo o sistema de esgotamento Belém, que possui 6.115 economias com água de chuva interligada na rede de esgoto (SANEPAR, 2012), revela uma contribuição de 4.158,20 L.s ${ }^{-1}$. Logo, uma vazão 5 vezes maior ( $400 \%$ de excedente) que a capacidade (840 L.s ${ }^{-1}$ ) de tratamento da estação de tratamento de esgoto Belém. Isso demonstra que o sistema separador absoluto não tem capacidade para operar nessas condições e descarrega, sem controle, esgoto diluído pelas cargas de chuva nos rios. 
Algumas ações poderiam ser tomadas para minimizar a contribuição da água de chuva na rede de esgoto, tais como:

1. Há a necessidade de criar campanhas de educação ambiental com alto impacto para esclarecer à população sobre as implicações negativas das ligações cruzadas de água de esgoto e da chuva;

2. A vistoria técnica de fiscalização deve ser de ação conjunta entre a empresa de saneamento e o município, pois somente o último tem competência legal para acesso às economias, notificação e posterior autuação nos casos de persistência das irregularidades;

3. Portas de visita para água de chuva e de esgoto devem ser normatizadas para viabilizar a análise de cruzamento de efluente com uso de corante;

4. A ação corretiva pode ser realizada com subsídio técnico da companhia de saneamento e recurso desta ou de órgãos públicos de modo a facilitar o pagamento, inclusive através de financiamentos especiais;

5. O auxílio técnico para tal regularização deve ser disponibilizado pela empresa de saneamento devido ao fato de que não são contratados profissionais habilitados para a realização das obras de reformas residenciais; e

6. Atualmente, o volume de esgoto é estimado pelo consumo de água tratada, o que não revela, perfeitamente, a contribuição da economia. Assim, a viabilidade de medição do esgoto deve ser estudada, pois seria a melhor solução para controlar a geração excedente de esgoto, bem como o afluxo de água da chuva.

\section{CONCLUSÕES}

Os dados georreferenciados das vistorias ambientais (SANEPAR, 2012) para afluxo de água de chuva predial na rede de esgoto foram adequados para criar um mapa de densidade de irregularidades para a bacia com maior histórico de acréscimo de vazão na estação de tratamento durante período de chuva, a bacia do Rio Belém e para identificar as áreas com maiores densidade de irregularidades.

Três áreas com alta densidade de irregularidades foram identificadas na bacia do Rio Belém. Uma vistoria ambiental complementar nas 426 economias do conjunto Assucena, pertencente à área maior densidade e a mais extensa, revelou que havia afluxo de água de chuva predial na rede de esgoto decorrente de obras civis de reformas inadequadas.

A maioria das economias pôde ser vistoriada $(71,1 \%)$, sendo que o teste de ligação cruzada com uso de corante pôde ser realizado em $47,4 \%$ do total. A impossibilidade de vistoria completa devido a imóvel fechado $(25,6 \%)$ pode ser atribuída parcialmente ao estilo de vida atual, que nem sempre permite a presença dos moradores no momento da visita. Houve uma pequena parcela dos moradores que não autorizou a vistoria ( $3,1 \%$ do total).

A entrevista dos moradores com ligações irregulares revelou desconhecimento da existência da ligação irregular (87\%) e dos problemas ambientais como extravasamentos do sistema de esgotamento sanitário (97\%), o que demonstra a necessidade imediata de ações de educação ambiental.

A medição de vazão na rede coletora, na saída do conjunto, deixa claro que há um acréscimo imediato de afluxo no sistema de transporte e que ocorreu extravasamento, uma vez que com diferentes volumes de precipitação a vazão não ultrapassa o valor de

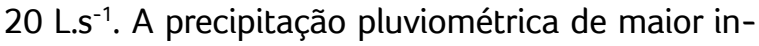
tensidade revelou um tempo de recorrência curto, o que reforça a gravidade da situação e que pode trazer prejuízo direto ao cidadão, como extravasamento em vias públicas e refluxo no interior de imóveis.

Levando em consideração a contribuição pluviométrica da precipitação de maior intensidade, a contribuição de 4.158 L.s $^{-1}$ foi calculada para toda a bacia do rio Belém. Esse valor é cerca de 5 vezes maior ( $400 \%$ excedente) do que a capacidade da estação de tratamento de esgoto Belém (840 L.s ${ }^{-1}$ ), destacando 
que o esgotamento sanitário é do tipo separador absoluto. A estimativa da contribuição parasitária proveniente das áreas particulares representa apenas $23 \%$ da contribuição de água de chuva, o que aponta outra frente de ação para evitar esse problema.

\section{REFERÊNCIAS ASSOCIAÇÃO BRASILEIRA DE NORMAS TÉCNICAS.(1989) NBR 10.844: Instalações prediais de água pluvial. Rio de Janeiro.}

AZEVEDO NETTO, J. M.(1979) Contribuições Indevidas para a Rede de Esgotos. In: Revista DAE, n.120, p. 36-38.

AZEVEDO NETTO, J. M. et al.(1998) Manual de Hidráulica. 8a ed. São Paulo: Editora Edgard Blücher.

BÉNÉDITTIS, J. de; BERTRAND-KRAJEWSKI, J. L.(2005) Infiltration in sewer systems: comparison of measurement methods. Water Science and Technology. Londres, v. 52, n. 3, 2005. Disponível em: $<$ httpapuss.insalyon.frnrl_030_infiltration_comparison_of_methods_SPN1.pdf>. Acesso em: 13/04/2013.

DIAS, I. C. A.(2011) A influência das águas pluviais no sistema de esgotamento sanitário, In: ASSEMAE, 33. 2011, Ibiporã. Disponível em:< www.semasa.sp.gov.br/scripts/ display .asp?idnot=431>. Acesso em: 20/04/2013.

ELLIS J. B.(2001) Sewer infiltration/exfiltration and interactions with sewer flows and groundwater quality. In: INTERURBA, 2, fevereiro de 2001, Lisboa. Disponível em: <http:apuss.insa-lyon.frgeneral\%20apuss\%20paper\%20for\%2010\%20icud\%20\%20 final\%20 revised\%20for\%20WPT.pdf>. Acesso em 13/04/2013.

FENDRICH, R. (1998) Chuvas intensas para obras de drenagem (no estado do Paraná). Curitiba: Champagnat.

FESTI, A. V. (2006) Estimativa da infiltração e do afluxo devidos a precipitação na rede coletora de esgoto sanitário em município de pequeno porte. 113 páginas. Dissertação - Universidade Federal de São Carlos, São Carlos, 2006. Disponível em: <www.ppgeu. ufscar.br/dissertacoes-e-teses/dissertacoes/defendidas/2006>. Acesso em: 04/04/2012.

FINNEY, R. L.; WEIR, M. D.; GIORDANO, F. R. (2005) Cálculo George B. Thomas. Tradução de Boschcov, Paulo; São Paulo: Editora Pearson Education do Brasil, p. 346-349.

JOHNSON, B.;TUOMARI, D. From theory to implementation - finding illicit connections. In: The Rouge River Project. Disponível em: <http://www.rougeriver.com/pdfs/illicit/wefspec98-02.pdf>. Acesso em 25/06/2014.

KACZOR, G. (2011) The effect of heavy precipitation on the infiltration and inflow into small sewage treatment plants in 2010. Infrastructure and ecology of rural areas. Kracovia, Nr.12,p.69-77, 2011. Disponível em: <http://agro.icm.edu.pl/agro/element/ bwmeta1 .element.dl-catalog-d4f6e67f-8439-4921-b956e8d9d8337864>. Acesso em 13/04/2013.

MACHADO, B et al. (2007) Minimization of inflow and infiltration in separate sanitary sewer systems. In: NOVATECH 2007 Sixth International Conference on Sustainable Techniques and Strategies in Urban Water Management. Session 9.3, p.1771-1778, 2007. Disponível em: < http://documents.irevues.inist.fr/bitstream/handle/2042/25169/1771_039machado.pdf> Acesso em 24/05/02014.

METCALF, L; EDDY, H. P.(1972) Determination of sewage flowrates. In: Wastewater Engineering: collection, treatment, disposal. United States of America: Copyright. p. 13-45.

METCALF, L; EDDY, H. P. Proyecto de alcantarillas. (1977) In: Tratamiento y depuracion de las aguas residuals. Tradução de: MONSORIU, J. DE D. T.; ALBERT, L. V.; Barcelona: Editora Labor. p. 109-133.

METCALF, L; EDDY, H. P. (1991) Wastewater Engineering: collection, treatment, disposal. 3rd ed. New York: McGraw-Hill.

METCALF, L; EDDY, H. P. (2003) Analysis and Selection of Wastewater Flowrates and Constituent Loadings. In: Wastewater Engineering Treatment and Reuse. Revisão: George Tchobanoglous, Franklin L. Burton e H. David Stensel, 4. ed. United States: Mcgraw-Hill Higher Education. p. 163 - 167.

RAYNAUD, O et al. (2008) A model-based assessment of infiltration and inflow in the scope of controlling separate sanitary overflows at pumping stations. In: 11th International Conference on Urban Drainage, Edinburgh, Scotland, UK, 2008. Disponível em:< http:// web.sbe.hw.ac.uk/staffprofiles/bdgsa/11th_International_Conference_on_Urban_Drainage_CD/ICUD08/pdfs/30.pdf>. Acesso em: 25/06/2014.

SANEPAR - Companhia Paranaense de Saneamento.(2012) Banco de Dados do Sistema de Gerenciamento Comercial (SGC).

SCHUSTER, Zair Lourival Luiz.(1994) Sanepar ano 30 resgate da memória do saneamento básico do Paraná. Curitiba: Arché - Assessoria em Mark. e Prod. Ltda.

TSUTIYA, M. T.; BUENO, R. C. R. (2004) Contribuição de águas pluviais em sistemas de esgotamento sanitário. In: Água Latinoamérica, v. 4, n. 4, p. 20-25, Julho/agosto 2004. Disponível em: <www. agualatinoamerica.comdocspdf070804\%20Sanitario\%20Brasil_ port.pdf>. Acesso em: 13/04/2013

TSUTIYA, M. T.; SOBRINHO, P. A. (2011) Coleta e transporte de esgoto sanitário. 3a ed. Rio de Janeiro: ABES.

TUOMARI, D. C.; THOMPSON, S. (2004) "Sherlocks of stormwater" Efective investigation techniques for illicit connection and discharge detection. Water Environment Federation. Alexandria, v. 16, p. 1252-1259, 01 janeiro 2004. Disponível em: <www.ingentaconnect.com/content/wef/wefproc/2004/00002004/00000016/ art00062 >. Acesso em: 08/08/2013.

ZHANG,Z. (2005) Flow data, inflow/infiltration ratio and autoregressive error models. J. Environmental. Engineering, v.131, n.3, p. 343-49. 